\title{
INSPIRATORY MUSCLE TRAINING IS INEFFECTIVE IN MECHANICALLY VENTILATED CRITICALLY ILL PATIENTS
}

\author{
Pedro Caruso, Silvia DC Denari, Soraia AL Ruiz, Karla G Bernal, Gabriela M \\ Manfrin, Celena Friedrich, and Daniel Deheinzelin
}

Caruso P, Denari SDC, Ruiz SAL, Bernal KG, Manfrin GM, Friedrich C. et al. Inspiratory muscle training is ineffective in mechanically ventilated critically ill patients. Clinics. 2005:60(6):479-84.

PURPOSE: Invasive mechanical ventilation is associated with complications, and its abbreviation is desirable. The imbalance between increased workload, decreased inspiratory muscle strength and endurance is an important determinant of ventilator dependence. Low endurance may be present due to respiratory muscle atrophy, critical illness, or steroid use. Specific inspiratory muscle training may increase or preserve endurance. The objective of the study was to test the hypothesis that inspiratory muscle training from the beginning of mechanical ventilation would abbreviate the weaning duration and decrease reintubation rate. As a secondary objective, we described the evolution of inspiratory muscle strength with and without inspiratory muscle training.

METHODS: Prospective, randomized clinical trial in an adult clinical-surgical intensive care unit. Twelve patients trained the inspiratory muscles twice a day, and 13 patients did not (control). Training was performed adjusting the sensitivity of the ventilator based on the maximal inspiratory pressure. Patients underwent daily surveillance of the maximal inspiratory pressure.

RESULTS: The weaning duration $(31 \pm 22 \mathrm{hr}$, control and $23 \pm 11 \mathrm{hr}$, training group; $P=.24)$ and reintubation rate (5 control and 3 training group; $P=.39$ ) were not statistically different. The maximal inspiratory pressure of the control group showed a trend toward a modest increase. In contrast, the training group showed a small decrease $(P=.34)$.

CONCLUSIONS: In acute critically ill patients, inspiratory muscle training from the beginning of mechanical ventilation neither abbreviated the weaning duration, nor decreased the reintubation rate. Inspiratory muscle strength tended to stay constant, along the mechanical ventilation, with or without this specific inspiratory muscle training.

KEYWORDS: Mechanical ventilation. Maximal inspiratory pressure. Ventilator weaning. Respiratory muscles.

Invasive mechanical ventilation (MV) is associated with complications, ${ }^{1}$ and its abbreviation lessens hospital-acquired infections and mortality. ${ }^{2}$ The imbalance between increased workload and inspiratory muscle endurance is an important determinant of ventilator dependence. ${ }^{3}$ Low endurance may be present due to respiratory muscle atrophy ${ }^{4}$ and dysfunction caused by the mechanical ventilation, ${ }^{5}$ critical illness, ${ }^{6}$ or steroids. ${ }^{7}$ Inspiratory muscle training may increase or preserve endurance.

Intensive Care Unit, Treatment and Research Center, Câncer Hospital - São Paulo/SP, Brazil.

Email:pedrocaruso@uol.com.br

Received for publication on June20, 2005.

Accepted for publication on September 30, 2005.
In ambulatory ${ }^{8,9}$ and mechanically ventilated patients with stable clinical conditions who had failed weaning attempts, ${ }^{10,11}$ endurance and strength were improved when muscle training was undertaken. In addition, more patients were successfully weaned. These studies were performed in long-term mechanically ventilated patients, and training began after failure of weaning. To our knowledge, no study has contemplated training from the beginning of mechanical ventilation in clinically stable patients undergoing prolonged mechanical ventilation. Moreover, in patients undergoing long-term mechanical ventilation, the evolution of endurance and strength of inspiratory muscles is unclear.

The main objective of the present study was to test the hypothesis that muscle training beginning 24 hours after 
starting mechanical ventilation in acute clinically stable patients expected to undergo prolonged mechanical ventilation would abbreviate the weaning duration and decrease the reintubation rate. As a secondary objective, we describe the evolution of inspiratory muscle strength with and without specific inspiratory muscle training.

\section{METHODS}

\section{Patients and Setting}

The study was conducted in a 13-bed clinical-surgical intensive care unit (ITC). The inclusion criterion was adults for whom prolonged mechanical ventilation ( $>72$ hours) was foreseen. The exclusion criteria applied to patients with flail chest, known coronary artery disease, alveolar hemorrhage, a mean arterial pressure under $70 \mathrm{~mm} \mathrm{Hg}$ after volume resuscitation, or previous peripheral neuromuscular disease. After randomization additional exclusion criteria were extubation before 72 hours, presence of hemoptysis during or immediately after inspiratory muscle training (IMT), worsening of pulmonary infiltrate after IMT without other possible cause, persistent hemodynamic instability, use of androgens, and skipping of more than 5 training sessions for any cause except appearance of signs of distress. The Ethics Committee of the Hospital approved the study, and an informed consent was obtained from the patient's next of kin.

\section{Design of the Study}

The study was a prospective randomized controlled trial. Each patient was randomly assigned to 1 of 2 groups: control or inspiratory muscle training (IMT). The control group patients did received no inspiratory muscle training, while the IMT group patients were trained twice a day.

Patients were mechanically ventilated with pressurecontrolled or volume-controlled ventilation for 24 hours (Siemens-Servo 300, Sweden) aiming to relieve an established or incipient respiratory muscle fatigue. Immediately after this rest period, a maximal inspiratory pressure (MIP) was measured using a unidirectional valve as previously described. ${ }^{12}$ Thereafter, MIP was measured daily in both groups and 30 minutes before extubation (final MIP). Both groups received pressure-control or volume-control ventilation until the criteria for weaning were fulfilled.

\section{Inspiratory Muscle Training Program}

The inspiratory muscle training program was based upon a previous IMT program that increased MIP and facilitated weaning in chronic respiratory failure patients with weaning failure. ${ }^{13}$ The respiratory therapists performed 2 exercise sessions, at $9 \mathrm{AM}$ and $5 \mathrm{PM}$, with the IMT group. Training was based on an overly insensitive trigger threshold, in order to cause inspiratory muscle overload. The pressure trigger sensitivity of the ventilator was adjusted to $20 \%$ of the first recorded MIP. In the first session, IMT was limited to 5 minutes; afterwards it was increased by 5 minutes at every session until it reached $30 \mathrm{~min}$. If a patient tolerated $30 \mathrm{~min}$ of IMT, the next session would be performed with an increase of $10 \%$ of the initial MIP. The maximal acceptable intensity was $40 \%$ of MIP. Patients who could not tolerate IMT with $20 \%$ of MIP for 5 minutes were trained with $10 \%$ of MIP.

The IMT session was terminated if a patient had any of the following signs: respiratory frequency of more than 30 breaths per minute, arterial saturation below 90\%, a tidal volume decrease of $30 \%$, systolic blood pressure above 180 $\mathrm{mm} \mathrm{Hg}$ or below $90 \mathrm{~mm} \mathrm{Hg}$, paradoxical breathing, uncoupling of inspiratory effort and ventilator triggering, agitation, tachycardia, hemoptysis, or diaphoresis. Patients presenting signs of distress began the next session with a shorter programmed time than that achieved in the previous training session.

Sedation was standardized for both groups with intravenous midazolam and fentanyl. The sedation was checked 3 times a day to achieve a Ramsay scale level ${ }^{14}$ between 2 and 5 .

\section{Weaning Program}

Patients were weaned from mechanical ventilation when all of the following conditions were fulfilled: improvement or resolution of the underlying cause of acute respiratory failure, ratio of partial pressure of arterial oxygen to the fraction of inspired oxygen above 200 with a positive end-expiratory pressure of $6 \mathrm{~cm} \mathrm{H}_{2} \mathrm{O}$, hemoglobin level above $8 \mathrm{~g}$ per/dL, cardiovascular stability, capacity to deal with airway secretion, and adequate level of consciousness. As criteria were fulfilled, ventilation was changed to pressure-support, which was initially set at $14 \mathrm{~cm} \mathrm{H}_{2} \mathrm{O}$ or adjusted to achieve a frequency of 25 breaths per minute if a higher pressure was needed. Pressure was reduced by $3 \mathrm{~cm} \mathrm{H}_{2} \mathrm{O}$ every 4 hours if the patient breathed at the previous pressure level with no sign of distress (the same criteria used for IMT distress). Patients who tolerated a pressure of $5 \mathrm{~cm} \mathrm{H}_{2} \mathrm{O}$ (or $8 \mathrm{~cm} \mathrm{H}_{2} \mathrm{O}$ in patients with chronic obstructive pulmonary disease) for 2 hours with no sign of distress were extubated. Failure of weaning was declared if reintubation was required within 48 hours.

\section{Statistical Analysis}

To assess the tendency of inspiratory muscle strength 
for each patient, we performed a linear regression of the daily measurements of MIP. A negative value of the coefficient meant a trend toward a decrease in MIP. Groups were compared using 1-way ANOVA for continuous variables and Fisher's exact test or chi-square test for discrete variables.

\section{RESULTS}

Forty patients were recruited consecutively over 18 months, and 25 completed the study. One patient was excluded because he skipped more than 5 sessions, 6 patients due to persistent hemodynamic instability, 2 due to extubation before 72 hours, and 6 due to withdrawal of life support. The characteristics of included and excluded patients at the beginning of the study were similar (Table 1).

Table 1 - General characteristics of patients at the beginning of the study. Values expressed as mean \pm standard deviation

\begin{tabular}{lllll}
\hline & IMT & Control & Excluded & $P$ \\
\hline $\mathrm{n}$ & 12 & 13 & 15 & \\
Male (\%) & $8(67)$ & $9(69)$ & $8(53)$ & .65 \\
Age (years) & $67 \pm 10$ & $66 \pm 17$ & $63 \pm 10$ & .70 \\
Apache II & $23 \pm 6$ & $24 \pm 7$ & $20 \pm 7$ & .36 \\
Acute lung injury score & $2.2 \pm 0.9$ & $1.6 \pm 0.6$ & $2.2 \pm 0.6$ & .11 \\
Chronic obstructive & 3 & 1 & 3 & .17 \\
$\quad$ pulmonary disease & & & & \\
Causes of mechanical & & & & .55 \\
$\quad$ ventilation & 10 & 12 & 13 & \\
Acute respiratory failure & 2 & 1 & 2 & \\
Decreased consciousness & 2 & 9 & 9 & .18 \\
Corticosteroids & 11 & 10 & 9 & .56 \\
$\quad$ Vasoactive drugs & 9 &
\end{tabular}

Vasoactive drugs $=$ adrenalin, noradrenalin, or dobutamine IMT = inspiratory muscle training group

The IMT was well-tolerated. A total of 167 training sessions was initiated and 144 completed (86\%). Twenty-three sessions were interrupted due to paradoxical breathing (9), tachypnea (6), desaturation (4), hemodynamic instability (3), and supraventricular tachycardia (1). Twelve programmed sessions were not initiated due to unstable clinical conditions or events not related to protocol, such as transportation to other hospital facilities.

The duration of weaning and the reintubation rate were not statistically different between the IMT and control groups (Table 2). The relative risk of IMT for reintubation was 0.65 (0.19-2.01).

The MIP coefficient of linear regression in the control group showed a trend toward a modest increase of MIP along the mechanical ventilation, while the IMT group showed a small decrease (Table 2 and Figure 1), but this difference was not statistically significant. Irrespective of
Table 2 - Reintubation rate, weaning and ventilation duration, and maximal inspiratory pressure tendency during the mechanical ventilation. Values expressed as mean \pm standard deviation

\begin{tabular}{llll}
\hline & IMT & Control & $P$ \\
\hline Reintubation rate (\%) & $3(25)$ & $5(38)$ & .67 \\
Weaning duration (hours) & $23 \pm 11$ & $31 \pm 22$ & .24 \\
Ventilation duration (hours) & $207 \pm 87$ & $235 \pm 193$ & .64 \\
MIP linear regression coefficient & $-0.07 \pm 3.82$ & $1.42 \pm 3.06$ & .342 \\
\hline
\end{tabular}

MIP = maximal inspiratory pressure

IMT $=$ inspiratory muscle training group

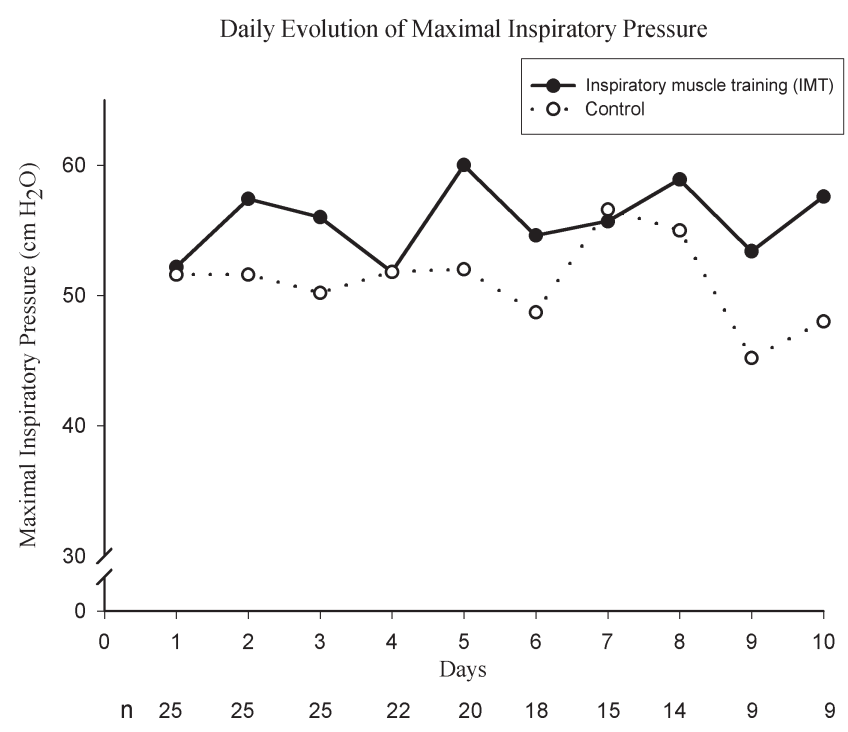

Figure 1 - Daily evolution of maximal inspiratory pressure in the first 10 days of mechanical ventilation. The value of each day represents the mean maximal inspiratory pressure in each group. The daily number of patients in each group remaining in the study recorded below the $\mathrm{x}$-axis

the group, the initial MIP and even the MIP at the day of extubation were below normal values (Figure 2).

\section{DISCUSSION}

Although the IMT program was well-tolerated and safe, in the present study IMT failed to abbreviate weaning and decrease the reintubation rate. Possible reasons include unfeasibility of muscular training in critically ill patients, overtraining, fatigue, or even the short duration/low load of the proposed training program.

Critically ill patients present with a decrease of the resting potential of muscle membranes, loss of the sodium-potassium gradient, and increase of the cytosolic calcium, leading to decreased muscle and nerve contractility, proteolysis, and mitochondrial density reduction. ${ }^{15}$ These alterations may prevent effective strength or endurance training in critically ill patients. 


\section{Initial and Final MIP}

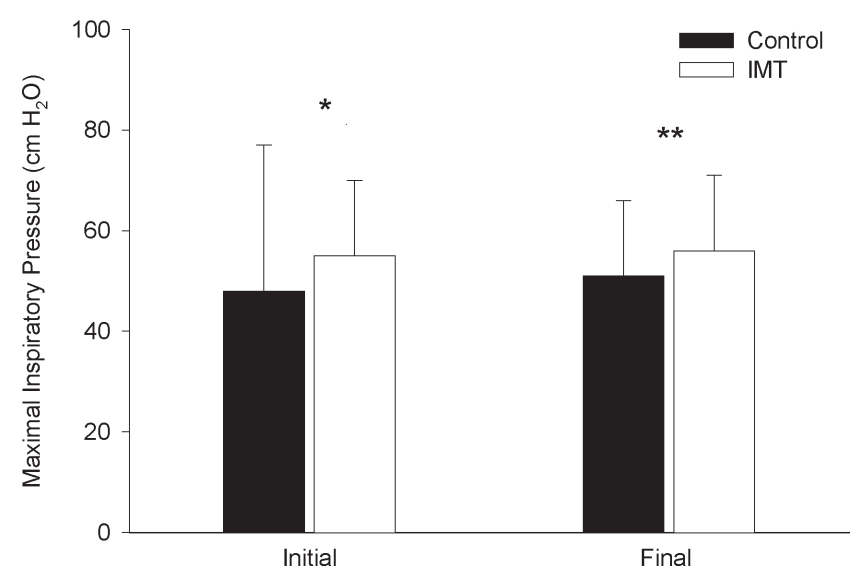

Figure 2 - Initial and final maximal inspiratory pressure. The left grouped bars represent initial maximal inspiratory pressure ( 24 hours after intubation). The right grouped bars represent final maximal inspiratory pressure (immediately before extubation)

* $P=.30$ for the difference between control and inspiratory muscle training (IMT) group (-48 \pm-29 and $-51 \pm-15 \mathrm{~cm} \mathrm{H}_{2} \mathrm{O}$, respectively)

** $P=.85$ for the difference between control and inspiratory muscle training (IMT) group $\left(-55 \pm-15\right.$ and $-56 \pm-15 \mathrm{~cm} \mathrm{H}_{2} \mathrm{O}$, respectively)

Assuming that the inspiratory muscles can be trained, an alternative hypothesis is overtraining. This is a problem of highly trained athletes, with a poorly understood etiology and difficult diagnosis. ${ }^{16}$ Since our patients underwent short-term training, with long recovery periods and brief training loads, overtraining was not expected, although it cannot be ruled out. Considering the hypothesis of fatigue, the training program could have perpetuated a previous low-level fatigue that was not reverted by 24 hours of muscular rest. ${ }^{17}$ Finally, endurance training requires sufficient load and duration of exercise in order to overload of the enzymatic systems and the electron transport system..$^{18}$ In our training program, load and duration may not have been sufficient.

We expected an initially normal MIP in our acutely ill patients; however, these patients exhibited a low MIP shortly after the start of mechanical ventilation. The probable causes are the already discussed reduction in muscle and nerve contractility of critically ill patients, ${ }^{15}$ an effect of the sedative on MIP, or the recently described detrimental effect of mechanical ventilation on the contractile properties of the diaphragm. ${ }^{5}$ However, it must be noted that on the day of extubation, MIP remained below the normal range in almost all patients. At this point, the sedative effect was minimal, and patients were more cooperative, but MIP remained below the normal range in more than $80 \%$ of patients, reflecting a real inspiratory muscle weakness.
An interesting result was the maintenance of MIP along with the mechanical ventilation in the untrained patients. It is a common belief that mechanical ventilation causes inspiratory muscle atrophy due to disuse. Although proven in heavily sedated and paralyzed animals with totally controlled ventilation, ${ }^{4}$ this hypothesis remains unproven in humans. In our study, patients were not heavily sedated or paralyzed, and assisted modes of ventilation were preferred.

One limitation of our study was the use of a volitional method to measure MIP. The initial low value and variability of MIP over the period of mechanical ventilation may have been due to sedation, lack of motivation, or oscillations in the level of consciousness. To avoid inconsistency in sedation, we checked it 3 times a day, and to counteract the lack of motivation and oscillations in conscious level, we measured MIP with a unidirectional valve. This method encompasses the physiologic response of increasing respiratory drive after a previous inefficient inspiration, thereby demanding less patient collaboration and has been shown to be reasonably reproducible. ${ }^{12}$ In addition, an endurance index would be more proper than a force measurement. Unfortunately, there is no reliable endurance index available to be applied in poorly collaborative mechanically ventilated patients.

Another limitation was the small sample size. Although, the IMT group showed a trend toward a lower reintubation rate and weaning duration, the fact that the inspiratory strength in this group tended to decrease during mechanical ventilation suggested a lack of beneficial effect on the IMT.

\section{CONCLUSIONS}

In acute critically ill patients, inspiratory muscle training from the beginning of mechanical ventilation neither abbreviated weaning duration nor decreased the reintubation rate. In acutely ill ventilated patients, initial and final maximal inspiratory pressure were lower than normal in the majority of patients and did not change during mechanical ventilation irrespective of inspiratory muscle training.

\section{ACKNOWLEDGMENTS}

The authors wish to thank: Leonice Böck, Eliana Louzada, Adriana Lários Nobrega, Fernanda Warken Rosa, Juliana Peroni Abrahão and Paula Regina de Mello Martins Ferreira. 
Caruso P, Denari SDC, Ruiz SAL, Bernal KG, Manfrin GM, Friedrich C. et al. O treinamento da musculatura inspiratória é ineficiente em pacientes graves submetidos à ventilação mecânica. Clinics. 2005:60(6):479-84.

OBJETIVO: A ventilação mecânica invasiva é associada a complicações, portanto sua abreviação é desejada. O desbalanço entre o aumento da carga sobre os músculos inspiratórios, a diminuição da força e a resistência muscular é determinante na dependência da ventilação. A baixa resistência muscular pode ser causada por atrofia muscular, pela doença grave ou pelo uso de corticoesteróides. O treinamento da musculatura inspiratória pode aumentar ou preservar a resistência. O objetivo principal do estudo foi testar a hipótese que o treinamento da musculatura inspiratória desde o início da ventilação iria abreviar o desmame da ventilação e diminuir a taxa de reintubação. Como objetivo secundário descrevemos a evolução da pressão inspiratória máxima com e sem treinamento da musculatura inspiratória. MÉTODOS: Estudo prospectivo e aleatorizado em unidade de tratamento intensivo Clínico-Cirúrgica. Doze pacientes treinaram a musculatura inspiratória duas vezes ao dia e treze não treinaram (controle). $\mathrm{O}$ treinamento foi realizado ajustando a sensibilidade do ventilador, baseando-se na pressão inspiratória máxima. Os pacientes tiveram sua pressão inspiratória máxima verificada diariamente.

RESULTADOS: A duração do desmame $(31 \pm 22$ controle e $23 \pm 11$ horas grupo treinamento; $p=0.24$ ) não foi estatisticamente diferente. A pressão inspiratória máxima do grupo controle teve leve tendência ao aumento, enquanto o grupo treinamento teve leve tendência à diminuição.

CONCLUSÃO: Em pacientes graves, o treinamento da musculatura inspiratória desde o início da ventilação mecânica não abreviou o desmame, nem diminuiu a reintubação. A pressão inspiratória máxima tendeu a manter-se constante ao longo da ventilação mecânica, com ou sem o treinamento inspiratório aplicado.

\section{PALAVRAS-CHAVE: Ventilação Mecânica. Desmame.} Músculos Respiratórios. Pressão Inspiratória Máxima.

\section{REFERENCES}

1. Pingleton SK. Complications of acute respiratory failure. Am Rev Respir Dis. 1988;137:1463-93.

2. Ferrer M, Esquinas A, Arancibia F, Bauer TT, Gonzalez G, Carrillo A, et al. Noninvasive Ventilation during Persistent Weaning Failure: A Randomized Controlled Trial. Am J Respir Crit Care Med. 2003;168:706.

3. Purro A, Appendini L, De Gaetano A, Gudjonsdottir M, Donner CF and Rossi A. Physiologic determinants of ventilator dependence in longterm mechanically ventilated patients. Am J Respir Crit Care Med. 2000;161:1115-23.

4. Anzueto A, Peters JI, Tobin MJ, de los Santos R, Seidenfeld JJ, Moore $\mathrm{G}$, et al. Effects of prolonged controlled mechanical ventilation on diaphragmatic function in healthy adult baboons. Crit Care Med. 1997;25:1187-90.

5. Shanely RA, Coombes JS, Zergeroglu AM, Webb AI and Powers SK. Short-duration mechanical ventilation enhances diaphragmatic fatigue resistance but impairs force production. Chest. 2003;123:195-201.
6. Latronico N, Fenzi F, Recupero D, Guarneri B, Tomelleri G, Tonin P, et al. Critical illness myopathy and neuropathy. Lancet. 1996;347:1579-82.

7. van Balkom RH, van der Heijden HF, van Herwaarden CL and Dekhuijzen PN. Corticosteroid-induced myopathy of the respiratory muscles. Neth J Med. 1994;45:114-22.

8. Smith K, Cook D, Guyatt GH, Madhavan J and Oxman AD. Respiratory muscle training in chronic airflow limitation: a meta- analysis. Am Rev Respir Dis. 1992;145:533-9.

9. Pardy RL, Rivington RN, Despas PJ and Macklem PT. The effects of inspiratory muscle training on exercise performance in chronic airflow limitation. Am Rev Respir Dis. 1981;123:426-33.

10. Aldrich TK and Uhrlass RM. Weaning from mechanical ventilation: successful use of modified inspiratory resistive training in muscular dystrophy. Crit Care Med. 1987;15:247-9.

11. Aldrich TK and Karpel JP. Inspiratory muscle resistive training in respiratory failure. Am Rev Respir Dis. 1985;131:461-2. 
12. Caruso P, Friedrich C, Denari SD, Ruiz SA and Deheinzelin D. The unidirectional valve is the best method to determine maximal inspiratory pressure during weaning. Chest. 1999;115:1096-1101.

13. Aldrich TK, Karpel JP, Uhrlass RM, Sparapani MA, Eramo D and Ferranti R. Weaning from mechanical ventilation: adjunctive use of inspiratory muscle resistive training. Crit Care Med. 1989;17:143-7.

14. Ramsay MA, Savege TM, Simpson BR and Goodwin R. Controlled sedation with alphaxalone-alphadolone. Br Med J. 1974;2:656-9.
15. Wagenmakers AJ. Muscle function in critically ill patients. Clin Nutr. 2001;20:451-4.

16. Petibois C, Cazorla G, Poortmans JR and Deleris G. Biochemical aspects of overtraining in endurance sports: a review. Sports Med. 2002;32:86778.

17. Laghi F, D'Alfonso $\mathrm{N}$ and Tobin MJ. Pattern of recovery from diaphragmatic fatigue over 24 hours. J Appl Physiol. 1995;79:539-46.

18. Faulkner JA. New perspectives in training for maximum performance. Jama. 1968;205:741-6. 